\title{
Employment and export specialisation along the development path: some robust evidence
}

\author{
Aleksandra Parteka
}

Published online: 17 November 2009

(C) Kiel Institute 2009

\begin{abstract}
This paper contributes to the literature on the evolution of overall specialisation along the process of economic development by simultaneously estimating 'specialisation curves' emerging from fully comparable employment and export statistics in a sample of 32 economies (1980-2000). We apply semiparametric estimation methods, which allow us to combine the flexibility of the estimation with the inclusion of country-specific effects, demonstrating that their omission can be the source of contradictions in nonparametrically revealed patterns of diversification along the path of growth. We find no strong support for a U-shaped pattern (which is very sensitive to the methodological setting applied) but rather a robust tendency towards manufacturing despecialisation in the initial phase of economic growth that is confirmed both by export and employment specialisation patterns.
\end{abstract}

Keywords Specialisation · Economic development ·

Semiparametric and nonparametric methods

JEL Classification $\mathrm{F} 43 \cdot \mathrm{O} 11 \cdot \mathrm{C} 14$

\section{Introduction}

This paper explores the theme of sectoral diversification and its evolution along the development path. The argument of specialisation (from now on we use the terms specialisation and diversification as antonyms) can be analysed from two different perspectives, depending on whether the subject of interest is its degree (thus if

\footnotetext{
A. Parteka $(\bowtie)$

Faculty of Management and Economics, Gdansk University of Technology,

Narutowicza 11/12, 80-233, Gdańsk, Poland

e-mail: aparteka@zie.pg.gda.pl
} 
a certain country specializes and to what extent) or its nature (thus in what kind of sectors economic activity is concentrated). In this paper we concentrate on the former aspect of economic activity distribution, still not so much explored in the empirical literature. Understanding such a relationship is important in the light of arguments suggesting not only that the nature of specialisation is important for economic growth (Grossman and Helpman 1991; Hausmann et al. 2007; Plümper and Graff 2001) but that also the degree of diversification is crucial from the perspective of economic progress (Acemoglu and Zilibotti 1997). It is especially relevant in low-income countries where high risk associated with low diversification can be particularly dangerous (Kalemli-Ozcan et al. 2003; Koren and Tenreyro 2007).

One of the problems that the empirical research on specialisation-GDP per capita nexus should address is the fact that the degree of economic structures' diversification can be examined from two distinct points of view: as a characteristic of an internal industrial structure or as a trade issue. Can we state that the degree of employment and export diversification are two phenomena evolving in parallel, or should they instead be treated separately as having different dynamics along the development path? The overview of existing studies (usually limiting the analysis to the data of one type) gives a rather mixed picture. There is some evidence for the decreasing degree of export intensity in Europe (Aiginger et al. 1999), in OECD countries (Laursen 2000), or in a heterogeneous group of developed and developing economies (Wörz 2005). At the same time, other studies confirm increasing trends of industrial specialisation in Europe (Aiginger and Davies 2004; Amiti 1999; Brülhart 1998). ${ }^{1}$

So far, few studies match specialisation patterns with GDP per capita performance at the international level, and there is still some incongruity in the conclusions drawn. The results vary depending on the set of data used (trade or industrial statistics), adopted measures of specialisation (relative or absolute, thus relating specialisation patterns to the general trend or not, respectively), and the inclusion or exclusion of country-specific effects in the estimation. It has been argued by means of nonparametric unconditional methodology ${ }^{2}$ (providing flexibility but not accounting for the importance of any other determinants of specialisation, not even country-fixed effects) that economies may undergo different stages of specialisation as they grow, first diversifying and then again specialising their industrial structure (Imbs and Wacziarg 2003; Koren and Tenreyro 2007) or trade composition (Cadot et al. 2007). At the same time a pattern of consistent decreasing specialisation has been revealed through semiparametric estimations ${ }^{3}$ performed with international trade statistics and taking into account country-specific effects (de Benedictis et al. 2009).

\footnotetext{
1 Increase in the degree of production specialisation does not necessarily imply rising export specialisation. In fact, the evidence from the European countries demonstrates that two aspects of specialisation may evolve in opposite directions with the rise in production specialisation and the tendency of de-specialisation in exports during the 1990s (Aiginger et al. 1999).

2 Usually the lowess (also known as loess) method introduced by Cleveland (1979) has been used.

${ }^{3}$ Generalised Additive Models have been used.
} 
It is possible that the differences in the conclusions drawn by various authors result only from the diversity of methodological and computational settings, but given the aforementioned variety of cross-country evidence, the omission of country-specific effects seems to be a serious problem. ${ }^{4}$ In order to address all of these points, we perform a fully comparable analysis of various (export and employment) aspects of specialisation along the GDP per capita expansion path within our perfectly homogeneous empirical setting. We apply a wide range of absolute and relative specialisation measures calculated for 32 economies over the years 1980-2000. To our knowledge, no systematic analysis of this kind has been performed so far. ${ }^{5}$

Since the very beginning we have not wanted to impose any limitation on the nature of the relationship between the extent of economic structures' diversification and corresponding development levels. In order to provide full comparability with the existing evidence, we start from the simplest unconditional nonparametric framework. Subsequently, however, we apply semiparametric estimation, which allows us to correct the flexible shape of the specialisation curves by including country-specific effects. Parametric methods are used as a supporting tool.

The rest of the paper is organised as follows: Sect. 2, following the introduction, describes basic concepts linked to the measurement of 'overall specialisation' and the composition of our data set. In Sect. 3 we briefly describe the methods of estimations we apply. In Sect. 4 we present results based on unconditional estimations of the specialisation-GDP per capita nexus, while in Sect. 5 we present robust results obtained by means of semiparametric estimation with country-fixed effects along with robustness checks. Concluding remarks are presented in Sect. 6. We do not find a robust support for a U-shaped pattern of specialisation along the path of growth, but rather a tendency towards manufacturing despecialisation in the initial phase of economic development, especially in relative diversification dynamics compared to the overall trend.

\section{Measurement issues}

\subsection{Concept of overall specialisation}

Overall specialisation can be roughly defined as "the extent to which a given country specialises its activities in a small number of industries or sectors"

\footnotetext{
${ }^{4}$ Only de Benedictis et al. (2009) directly incorporate country-fixed effects into the flexible estimation of export specialisation curves.

${ }^{5}$ Some specialisation studies include 'sensitivity analysis,' which extends the basic data set and compares the outcomes obtained with various types of data (value added, output, employment, and trade). However, as a result of the differences in the time span, the set countries, or the level of sectoral disaggregation it is impossible to confront directly the growth effects of trade and employment specialisation. Brülhart $(1998,2001)$ matches employment and export data to study geographical location patterns in the EU; Midelfart-Knarvik et al. (2000) use EU production and trade data, but they do not explore the link between emerging specialisation patterns and GDP per capita performance. We have not encountered in the existing literature any simultaneous estimation of export and employment 'specialisation curves' that take into account the importance of country-fixed effects.
} 
(Aiginger and Davies 2004: 235) and is the opposite of the degree of economic structures' diversification. Consequently, in our case a country is said to be specialised in a particular industry if this industry attains a high share in total manufacturing of the respective country; i.e. with respect to the employment structure, a country is said to be highly specialised if a limited number of industries account for a large share of total employment. ${ }^{6}$ Analogical definitions can be formulated for export specialisation.

\subsection{Absolute and relative measures of specialisation}

There are several measures of specialisation, usually formulated as synthetic indexes constructed for a single country in a given year. These instruments can be divided into two broad categories classified as absolute and relative indexes. Absolute measures of specialisation show how different the distribution of sector shares is from a uniform distribution (when each sector has the same share in total employment or trade, accordingly) and describe the degree of economic activity diversification in a given country, with no comparison to 'world' trends. The indexes of the second type-relative ones-relate the sectoral structure of a particular country to the common benchmark (which may be perceived as a typical degree of specialisation in the country sample) and measure how 'diversified' the economic structure of a given country is from the rest of the countries considered. We calculate practically all measures that have been used in the specialisation literature.

Consider $n$ industries (sectors) present in $m$ countries and define the share of employment $(E)$ in industry $i=1,2, \ldots, n$ in total employment of country $j=1,2, \ldots, m$ as:

$$
s_{i j}=E_{i j} / \sum_{i} E_{i j} .
$$

Hence, we define the 'world' typical share of industry $i$ in total 'world"7 employment:

$$
w_{i}=\sum_{j} E_{i j} / \sum_{i} \sum_{j} E_{i j}
$$

Analogical shares can be defined with export data. We report four absolute and three relative indexes of specialisation calculated according to the formulas in Table 1. The former indexes measure the dispersion of (1) across the whole economy, and

\footnotetext{
${ }^{6}$ We thank the anonymous referee for clearing this point. Note the difference with the concept of concentration defined as "the extent to which activity in a given industry is concentrated in a few countries" (Aiginger and Davies 2004: 235). The link between sectoral specialisation and geographical concentration is presented in the New Economic Geography models (Krugman 1991), which highlight the existence of economies of agglomeration and where geographic concentration of economic activity may imply specialisation. It happens if agglomeration forces (such as the existence of specialised suppliers or specific labour markets) originate from spillovers that affect firms belonging to the same industry.

7 Note that 'world' here is treated conventionally because it consists of only those $m$ countries that are included in our analysis and not all world economies. As a result, the 'world' benchmark $w_{i}$ we use is not the real world industry share but rather the share referring to its part consisting of $m$ economies.
} 
Table 1 Overall specialisation measures

Absolute specialisation measure

1. Herfindahl index

2. Absolute Gini index

3. Coefficient of variation

4. Absolute Theil entrophy index Relative specialisation measure

1. Dissimilarity index

2. Relative Gini index

3. Relative Theil entrophy index

$$
\begin{aligned}
& \operatorname{Herf}_{j}=\sum_{i=1}^{n}\left(s_{i j}^{2}\right) \\
& \text { AbsGini }_{j}=\left(\frac{2}{n^{2} \overline{E_{j}}}\right) \sum_{i=1}^{n}\left[\left(i-\frac{n+1}{2}\right) E_{i j}\right] \quad \text { AbsGini }_{j} \in\langle 0,1\rangle \\
& C V_{j}=\left[\sqrt{\left(\frac{1}{n} \sum_{i=1}^{n}\left(E_{i j}-\overline{E_{j}}\right)^{2}\right)}\right] / \overline{E_{j}} \quad C V_{j} \in\langle 0, \infty\rangle \\
& \text { AbsTheil } l_{j}=\frac{1}{n} \sum_{i=1}^{n}\left(\frac{E_{i j}}{\overline{E_{j}}} \cdot \ln \frac{E_{i j}}{\overline{E_{j}}}\right) \\
& \text { AbsTheil }_{j} \in\langle 0, \ln (n)\rangle \\
& D I_{j}=\sum_{i=1}^{n}\left|s_{i j}-w_{i}\right| \\
& \text { RelGini } i_{j} \text {-as in Amiti (1999) }{ }^{\mathrm{b}} \quad \text { RelGini }_{j} \in\langle 0,1\rangle \\
& \operatorname{Re} l \text { Theil }_{j}=\sum_{i=1}^{n}\left(s_{i j} \cdot \ln \frac{s_{i j}}{w_{i}}\right) \\
& \text { RelTheil } l_{j} \in\langle 0, \ln (n)\rangle
\end{aligned}
$$

\begin{abstract}
${ }^{\text {a }}$ Here we have adopted employment $(E)$ notation, analogical measures have been calculated with export data $(X) ; i$ refers to sectors and $j$ to countries. Shares $s_{i j}$ and $w_{i}$ defined in the text

b The first step involves constructing of a Lorenz curve by ranking sectoral Balassa indexes $(B I)$ in ascending order, representing the cumulative of the denominator of $B I$ on the horizontal axis and the cumulative of the numerator of $B I$ on the vertical axis. Secondly, the relative Gini index is calculated as twice the area between the Lorenz curve and the 45 degree line (we have used approximate trapezoidal formula) which is associated with a case when country $j$ has the same pattern of Revealed Comparative Advantage as the benchmark ('world')
\end{abstract}

the latter ones refer (1) to (2). Our set of absolute indexes of specialisation includes the following: Herfindahl index (Herf), absolute Gini index (AbsGini), coefficient of variation $(C V)$, and absolute Theil entrophy ${ }^{8}$ index (AbsTheil). We also calculate relative measures of specialisation: dissimilarity index $(D I)$, relative Gini index (RelGini), and relative Theil entrophy index (RelTheil). ${ }^{9}$ All these measures are positively related to the degree of overall specialisation: the bigger the value of an index, the more specialized (hence, the least diversified) is the economic structure of a country.

\title{
2.3 Data and panel composition
}

Since the very beginning we aimed at performing an analysis that eliminates methodological differences at the start. It meant the creation of fully comparable export and employment sectoral data sets, including the data for the same countries and for overlapping time periods. The final selection of countries and the time span of our analysis (1980-2000) is based on the thorough comparison of the two basic data sources we use: the United Nations Industrial Statistics Database (UNIDO 2006) and

\footnotetext{
${ }^{8}$ Entrophy is a technical name meaning the 'degree of disorder' (Cowell 1995: 48).

${ }^{9}$ Specialisation indexes are based on standard measures of economic inequality and defined as in Cowell (1995). For complete definitions of various alternative statistical instruments used in the analysis of specialisation patterns, see de Benedictis and Tamberi (2004) or Iapadre (2001).
} 
Table 2 List of countries and adopted abbreviations

\begin{tabular}{|c|c|c|c|}
\hline$B O L$ Bolivia $^{a}$ & FIN Finland & $I R N$ Iran, Islamic Rep ${ }^{\mathrm{e}}$ & MAC China, Macao SAR \\
\hline CAN Canada & FRA France & $I S R$ Israel & NOR Norway \\
\hline CHL Chile ${ }^{\mathrm{b}}$ & $G B R$ United Kingdom & ITA Italy & PRT Portugal \\
\hline CHN China ${ }^{\mathrm{c}}$ & $H K G$ China, Hong Kong & $J O R$ Jordan & $S G P$ Singapore \\
\hline COL Colombia & HUN Hungary ${ }^{\mathrm{d}}$ & $J P N$ Japan & SWE Sweden \\
\hline CYP Cyprus & $I N D$ India & KEN Kenya & TUR Turkey $^{\mathrm{g}}$ \\
\hline$E C U$ Ecuador & IDN Indonesia & $K O R$ Korea, Rep. of & $U R Y$ Uruguay $^{\mathrm{h}}$ \\
\hline ESP Spain & $I R L$ Ireland & $K W T$ Kuwait $^{\mathrm{f}}$ & USA United States of America \\
\hline
\end{tabular}

a Not in export data set 1980-1990

b Not in export data set 1980-1982

c Not in export data set 1980-1986

d Not in export data set 1980-1991

e Not in export data set 1980-1996

f Not in export data set 1980-1986 and 2000

g Not in export data set 1980-1984

h Not in export data set 1980-1982

the United Nations Commodity Trade Statistics Database (UN COMTRADE) from UNSD (2007). ${ }^{10}$ In the end, our analysis covers 32 world economies (Table 2) at various levels of GDP per capita, ranging in the base year (2000) from 751 int. US\$ (China in 1980) to 34,364 int. US\$ (USA in 2000), for which we were able to obtain complete disaggregated industrial and export statistics for overlapping time periods.

The analysis is restricted to manufacturing sectors ${ }^{11}$ that are expected to be less dependant on geographical and climatic conditions. As for the disaggregation level, the advantage of the data set we use is that, both for employment and for export statistics, we manage to maintain exactly the same sectoral disaggregation scheme (ISIC Rev.2, 3-digit). ${ }^{12}$ We reorganized the original data in order to provide full comparability between employment and export sectoral data sets, and in the end we base the calculation of synthetic measures of overall specialisation on the data for

\footnotetext{
${ }^{10}$ We have analysed the coverage of employment, value added, and output series for every single country present in UNIDO Rev.2 database, and what emerges is that sectoral statistics are complete only for a small sample of world economies. By 'complete' we mean that for a given year the employment, output, or value added data is available for at least two thirds of ISIC Rev.2, 3-digit sectors. Theoretically, the UNIDO database includes industrial statistics for more than 160 world economies. In reality, only one-third of them report complete employment series for more that 20 years between 1980 and 2005. Out of these, we have chosen those countries for which complete trade statistics were also available.

11 ISIC Rev.2, 3 digit-codes 311-390.

12 This was possible thanks to the use of trade data classified not, as usual, according to the SITC system (Standard International Trade Classification) but according to the ISIC division (International Standard Industrial Classification). Such 'reclassified' export data series come from the World Bank's Database available through WITS (World Integrated Trade Solutions). We use Revision 2 because many countries do not report complete statistics classified according to the newer Revision 3; thus, Revision 2 provides a more complete coverage of data in terms of countries covered. We preferred to include in the analysis as many countries as possible, maintaining also the relatively long time span (20 years) needed for the analysis of this kind. We thank the referee for raising this point.
} 
Table 3 List of manufacturing sectors and adopted aggregations

\begin{tabular}{ll}
\hline Manufacturing sector (with code) & $\begin{array}{c}\text { Corresponding ISIC Rev. 2, 3-digit codes } \\
\text { and names (adopted aggregations) }\end{array}$ \\
\hline 1. Food, beverages and tobacco (311b) & $\begin{array}{c}311 \text { Food products }+313 \text { beverages } \\
\end{array}$ \\
& +314 tobacco \\
2. Textiles (321) & 321 Textiles \\
3. Clothes, leather products and footwear (322b) & footwear + 323 leather \\
& products +324 footwear, \\
& except rubber or plastic \\
4. Wood products, except furniture (331) & 331 Wood products, except furniture \\
5. Furniture, except metal (332) & 332 Furniture, except metal \\
6. Paper and products (341) & 341 Paper and products \\
7. Printing and publishing (342) & 342 Printing and publishing \\
8. Chemicals (351a) & 351 Industrial chemicals +352 other chemicals \\
9. Rubber products (355) & 355 Rubber products \\
10. Plastic products (356) & 356 Plastic products \\
11. Pottery, china, earthenware, & 361 Pottery, china, earthenware +362 glass \\
glass and other similar products (361b) & and products +369 other non-metallic \\
& mineral products \\
12. Iron, steel and non ferrous metals (371a) & 371 Iron and steel +372 non-ferrous metals \\
13. Fabricated metal products (381) & 381 Fabricated metal products \\
14. Machinery (except electrical), & 382 Machinery, except electrical \\
professional and scientific equipment (382f) & +385 professional \\
& and scientific equipment \\
15. Machinery, electric (383) & 383 Machinery, electric \\
16. Transport equipment (384) & 384 Transport equipment \\
17. Other manufacturing (390) & 390 Other manufacturing products \\
&
\end{tabular}

17 manufacturing sectors (Table 3). It allows us to make direct comparisons between results based on two types of specialisation measures (relative and absolute), as well as between the specialisation patterns emerging from various data (employment and export statistics). ${ }^{13}$

To summarize, we have a perfectly comparable-across time, countries, and industries—set of employment and export statistics. ${ }^{14}$ Additional data (GDP per capita in int. US\$2000) come from Penn World Table 6.2 (Heston et al. 2006).

\footnotetext{
${ }^{13}$ Because of the presence of missing data, we eliminated two sectors ('Petroleum refineries' and 'Miscellaneous petroleum and coal products': ISIC codes 353 and 354, respectively). Some original ISIC industries have been aggregated in order to have the same combination of sectors for all countries (see Table 3).

${ }^{14}$ The unique characteristic of the data we use is the fact that by choosing this very set of countries, years, and sectors we have managed to reduce noticeably the number of missing values ( $1.3 \%$ of total 24,395 sectoral observations). In the employment data set 141 out of 11,424 sectoral observations (1.2\%) have been filled in through standard interpolation/ extrapolation techniques. In the export data set, $1.39 \%$ (181 out of 12,971 cells) had been filled in.
} 


\section{Flexible estimation techniques: methodology}

\subsection{Nonparametric methods of estimation}

We are interested in methods that do not assume any particular functional form and that allow a flexible analysis. In case of built-in (or suspected) nonlinearity present in the data, nonparametric regression techniques (Pagan and Ullah 1999) provide useful and simple tools for modelling and exploring such data. A standard linear regression would assume that the mean of the response variable $Y$ (in our case, the degree of specialisation, $S P E C$ ) is a linear function of a single predictor $X$ (in our case, GDP per capita):

$$
E(Y \mid X)=\alpha+X \beta
$$

where parameters $\alpha$ and $\beta$ are usually estimated by least squares. In order to reveal the functional dependence of $E(Y)$ on $X$ without imposing the rigid parametric assumption about that dependence, we can consider its nonparametric representation of the following form:

$$
E(Y \mid X)=f(X)
$$

where $f(X)$ is an unspecified function and a smooth is defined as an estimate of $f(X)$. The function can be estimated by a number of smoothers, which are nonparametric tools used for estimating the trend through use of piecewise regression. ${ }^{15}$ In our case, we can apply such nonparametric formulation to consider the model:

$$
E(S P E C \mid G D P p c)=f(G D P p c)
$$

where $f($.) is an unspecified function, SPEC is represented by one of the measures of overall specialisation calculated previously (as in Table 1), and GDPpc denotes GDP per capita level (int. US\$, 2000). Note that we match each country's specialisation level with output per capita at any given moment of time and not using a time trend. In order to compare our results with those of the other authors, at the start we implement a locally weighted smoother (also known as lowess or loess) as introduced by Cleveland (1979). ${ }^{16}$

However, such unconditional nonparametric methods, albeit relaxing the assumption of a linear relationship between the response and the predictor, are

\footnotetext{
${ }^{15}$ In the first step 'neighbourhoods' of points around each $x$ of interest are defined by span value, and then a separate linear regression is fitted in each neighbourhood. See Schimek (2000) for a thorough description of all commonly used smoothing techniques.

${ }^{16}$ It is computed in the following steps (Hastie and Tibshirani 1990: 30): Smooth $s\left(x_{0}\right)$ uses $k$ nearest neighbours (closest points to $x_{0}$ ) denoted by $N\left(x_{0}\right)$, which are identified at the beginning. The number of nearest neighbours, usually expressed as a percentage of the data points (span), is the smoothing parameter. The choice of span parameters is crucial, as a wider neighbour will produce a smoother function but will track the data less closely (so-called 'bias and variance trade-off'). Next, the distance of the furthest near-neighbour from $x_{\mathrm{o}}$ is computed. Weights $w_{i}$ are given to each point in $N\left(x_{0}\right)$ using the tricube weight function. Such a weighting scheme provides decreasing weights (and less relative importance) on observations that are more distant from $x_{0}$. Finally, $s\left(x_{0}\right)$ is a fitted value at $x_{0}$ coming from the weighted least squares fit of $Y$ to $X$ confined to $N\left(x_{0}\right)$. The procedure is repeated for each observation (the number of regressions is equal to the number of observations), and the fitted values are used for the construction of the nonparametric curve representing the relationship between $Y$ and $X$.
} 
limited. They do not take into account any country-specific factors influencing the evolution of specialisation patterns. Consequently, exactly as parametric results based on pooled data, lowess curves may hide a great degree of cross-country heterogeneity. We argue that a correctly estimated 'specialisation curve,' which aims at describing the evolution of economic activity diversification as the level of GDP per capita grows in a 'typical' country, must take into account at least countryspecific effects. In order to match the flexibility of estimation with the possibility of accounting for such country heterogeneity, we opt for the semiparametric estimation.

\subsection{Semiparametric methodology}

We apply semiparametric estimation in the form of a Generalised Additive Model (GAM), introduced by Friedman and Stuetzle (1981) and developed by Hastie and Tibshirani (1990). Additive models can be summarised in a few points (Schimek and Turlach 2000). The aim is to study the structural relationship between the response variable $Y$ and the vector of $p$ covariates $\mathbf{X}=\left(X_{1}, \ldots, X_{p}\right)^{\mathrm{T}}$ via $m(\mathbf{x})=E(Y \mid \mathbf{X}=\mathbf{x})$ where $\mathbf{x}=\left(x_{1}, \ldots, x_{p}\right)^{\mathrm{T}}$ and $m(\mathbf{x})=m\left(x_{1}, \ldots, x_{p}\right)$. In the usual multiple linear regression $m(\mathbf{x})$ is linear and additive in the predictors:

$$
Y=m(\mathbf{X})+e
$$

where $\mathrm{E}(e)=0$ and $\operatorname{Var}(e)=\delta^{2}$. In an additive specification only additivity is required, and the components are allowed to take on nonparametric forms, i.e. $Y$ is approximated by the following model:

$$
m(\mathbf{X}) \approx g(X)=g_{0}+\sum_{j=1}^{p} g_{j}\left(X_{j}\right)
$$

where $g_{0}$ is a constant and $g_{j} s$ are univariate smooth functions. What follows is that under identifiability for any $k=1, \ldots, p$

$$
E\left(Y-g_{0}-\sum_{j \neq k} g_{j}\left(X_{j}\right) \mid X_{k}\right)=g_{k}\left(X_{k}\right)
$$

which suggests the adoption of an iterative procedure for the estimation of the univariate functions $g$ (corresponding to the explanatory variables). The generalised version of an additive model (GAM) becomes:

$$
E(Y \mid \mathbf{X}=\mathbf{x})=G\left(g_{0}+\sum_{j=1}^{p} g_{j}\left(X_{j}\right)\right)
$$

where $G($.$) is a fixed link function. { }^{17}$

A special case, which we apply in the estimation of a semiparametric specialisation curve, occurs when only one predictor function is evaluated nonparametrically while

\footnotetext{
17 The fitting of GAM consists of two steps: estimating the additive predictor by solving the system of normal equations and linking it to the function $G($.$) in an iterative manner through the so-called local$ scoring algorithm (for details on the fitting procedure and GAM models in general see Schimek and Turlach (2000) or Wood (2006); for examples of applications see Hastie and Tibshirani (1987)).
} 
all the remaining ones enter as a linear combination. It means that into the right-hand side of our model linking specialisation and the development level, we can introduce GDP per capita in a flexible form (as a nonparametric component) and a set of standard country dummies (as parametric components). In other words, we are able to control unconditional specification (5) for the importance of country-specific effects. In particular, we apply the following semiparametric formulation:

$$
E(S P E C \mid G D P p c, \boldsymbol{D})=f(G D P p c)+\boldsymbol{D} \gamma
$$

where $S P E C$ is represented by one of our overall specialisation measures, GDPpc denotes GDP per capita (US\$, 2000), and $\boldsymbol{D}$ is a set of control variables (in our case, country dummies). ${ }^{18}$ Our main interest is to reveal the shape of the unknown function $f($.$) describing the evolution of overall specialisation along the develop-$ ment path: it is estimated from the data through a backfitting procedure that was introduced as an iterative fitting procedure within the framework of nonparametric multidimensional regression (Friedman and Stuetzle 1981). It determines estimates for the covariates in a successive manner, using the currently available information from all covariates except the one for which estimates have just been computed. ${ }^{19}$

In this specific example, the algorithm separates the parametric and nonparametric parts of the fit. The parametric part is estimated using weighted linear least squares within the backfitting algorithm, while the nonparametric part is fitted by iteratively smoothing partial residuals and represented graphically through a semiparametric version of partial residuals' plot. ${ }^{20}$

\section{Overall specialisation along the development path: first evidence}

Summary statistics of all measures obtained with employment and export statistics are presented in Table 4. All pairwise correlation coefficients between various specialisation indexes are presented in Table $5 .^{21}$

\footnotetext{
${ }^{18}$ So far, in the existing literature on the topic only de Benedictis et al. (2009) have applied a similar flexible approach to the estimation of the relationship between specialisation and GDP per capita levels, but they focus on trade patterns only.

${ }^{19}$ For a detailed formal description see Hastie and Tibshirani (1990: 89-91) or Schimek and Turlach (2000: 300-301).

${ }^{20}$ Note that this is not the same as the standard partial residual plot used as a postestimation instrument in the linear regression analysis. A partial residual plot of a linear fixed-effects model would allow the detection of nonlinearity in the data only at a postestimation stage, while GAM procedure flexibly fits the model jointly by iteratively smoothing partial residuals. Moreover, we would anyway need to apply some nonparametric tool to approximate the shape of the relationship resulting from a set of points plotted in a partial residual plot. Usually lowess approximation is used.

21 Note that the choice of a particular index can be relevant for the final conclusions drawn. We observe strong correlations within the groups of various absolute indexes, as long as they are all calculated with the data of one type (employment or export). The same is true for relative measures. However, weak correlations between DI, RelGini, and RelTheil on one side and Herf, AbsGini, CV and AbsTheil on the other suggest that the passage from relative to absolute measures is likely to modify the outcomes of the specialisation analysis. We have also computed Spearman correlation coefficients (available on request). The pattern of correlations is similar.
} 
Table 4 Summary statistics for employment and export specialisation indexes (1980-2000)

\begin{tabular}{|c|c|c|c|c|c|}
\hline Specialisation measure & Mean & Std. Dev. & Min. & Max. & Obs. \\
\hline \multicolumn{6}{|c|}{ Employment specialisation $^{\mathrm{a}}$} \\
\hline \multicolumn{6}{|l|}{ Herf } \\
\hline Overall & 0.122 & 0.056 & 0.072 & 0.477 & $N=672$ \\
\hline Between & & 0.055 & 0.075 & 0.379 & $n=32$ \\
\hline Within & & 0.016 & -0.044 & 0.220 & $T=21$ \\
\hline \multicolumn{6}{|l|}{ AbsGini } \\
\hline Overall & 0.463 & 0.099 & 0.267 & 0.816 & $N=672$ \\
\hline Between & & 0.097 & 0.287 & 0.778 & $n=32$ \\
\hline Within & & 0.026 & 0.309 & 0.548 & $T=21$ \\
\hline \multicolumn{6}{|l|}{$\mathrm{CV}$} \\
\hline Overall & 1.007 & 0.365 & 0.497 & 2.749 & $N=672$ \\
\hline Between & & 0.357 & 0.542 & 2.393 & $n=32$ \\
\hline Within & & 0.095 & 0.280 & 1.364 & $T=21$ \\
\hline \multicolumn{6}{|l|}{ AbsTheil } \\
\hline Overall & 0.402 & 0.227 & 0.117 & 1.573 & $N=672$ \\
\hline Between & & 0.222 & 0.136 & 1.352 & $n=32$ \\
\hline Within & & 0.059 & -0.165 & 0.624 & $T=21$ \\
\hline \multicolumn{6}{|l|}{ DI } \\
\hline Overall & 0.558 & 0.226 & 0.212 & 1.395 & $N=672$ \\
\hline Between & & 0.222 & 0.285 & 1.327 & $n=32$ \\
\hline Within & & 0.055 & 0.164 & 0.704 & $T=21$ \\
\hline \multicolumn{6}{|l|}{ RelGini } \\
\hline Overall & 0.369 & 0.137 & 0.147 & 0.812 & $N=672$ \\
\hline Between & & 0.135 & 0.195 & 0.784 & $n=32$ \\
\hline Within & & 0.033 & 0.174 & 0.450 & $T=21$ \\
\hline \multicolumn{6}{|l|}{ RelTheil } \\
\hline Overall & 0.278 & 0.259 & 0.036 & 1.586 & $N=672$ \\
\hline Between & & 0.256 & 0.064 & 1.411 & $n=32$ \\
\hline Within & & 0.059 & -0.471 & 0.458 & $T=21$ \\
\hline \multicolumn{6}{|l|}{ Export specialisation $^{\mathrm{b}}$} \\
\hline \multicolumn{6}{|l|}{ Herf } \\
\hline Overall & 0.191 & 0.106 & 0.085 & 0.903 & $N=606$ \\
\hline Between & & 0.089 & 0.112 & 0.492 & $n=32$ \\
\hline Within & & 0.055 & -0.075 & 0.601 & Tbar $=19$ \\
\hline \multicolumn{6}{|l|}{ AbsGini } \\
\hline Overall & 0.618 & 0.106 & 0.085 & 0.903 & $N=606$ \\
\hline Between & & 0.089 & 0.112 & 0.492 & $n=32$ \\
\hline Within & & 0.055 & -0.075 & 0.601 & Tbar $=19$ \\
\hline \multicolumn{6}{|l|}{$\mathrm{CV}$} \\
\hline Overall & 1.464 & 0.099 & 0.376 & 0.924 & $N=606$ \\
\hline Between & & 0.089 & 0.452 & 0.812 & $n=32$ \\
\hline Within & & 0.046 & 0.404 & 0.781 & Tbar $=19$ \\
\hline
\end{tabular}


Table 4 continued

\begin{tabular}{llllll}
\hline Specialisation measure & Mean & Std. Dev. & Min. & Max. & Obs. \\
\hline AbsTheil & & & & & \\
Overall & 0.754 & 0.489 & 0.692 & 3.904 & $N=606$ \\
Between & & 0.431 & 0.977 & 2.701 & $n=32$ \\
Within & & 0.229 & 0.503 & 2.667 & Tbar $=19$ \\
DI & & & & \\
Overall & 0.796 & 0.340 & 0.249 & 2.541 & $N=606$ \\
Between & & 0.296 & 0.363 & 1.518 & $n=32$ \\
Within & & 0.168 & 0.069 & 1.782 & Tbar $=19$ \\
RelGini & & & & $N=606$ \\
Overall & 0.498 & 0.362 & 0.183 & 1.805 & $N=32$ \\
Between & & 0.356 & 0.249 & 1.513 & $n=19$ \\
Within & 0.105 & 0.365 & 1.211 & Tbar $=19$ \\
RelTheil & & & & $N=606$ \\
Overall & & 0.196 & 0.123 & 0.928 & $N=32$ \\
Between & 0.601 & 0.050 & 0.195 & 0.844 & $n$ \\
Within & & 0.632 & Tbar $=19$ \\
\hline
\end{tabular}

${ }^{\mathrm{a}}$ UNIDO, ISIC Rev.2, 3-digit

b UN COMTRADE, ISIC Rev.2, 3-digit

We match these specialisation measures with corresponding GDP per capita levels at any point of time with the aim of revealing 'specialisation curves'. In order to give an example of cross-country specificity of specialisation evolution along the path of growth, we first present evidence for selected economies and then pass towards the estimation of general 'specialisation curves'.

\subsection{Country-specific trends}

Country-level evidence confirms that when different countries find themselves at different stages in the development process, this is reflected in their patterns of specialisation, but some underlying specific effects also play a role. The following figures demonstrate the evolution of overall specialisation in two dynamic economies (namely China, Fig. 1, and USA, Fig. 2) that have followed the course of growth along very different levels of GDP per capita. Thanks to the adoption of the unifying framework, we can directly confront employment and export specialisation patterns revealed with absolute and relative measures (here: Gini index).

When measured in absolute terms, China demonstrates a kind of U-shaped path of exports diversification (Fig. 1, left plot), but when we refer its degree of trade specialisation to the world benchmark (Fig. 1, right plot), we can observe a decreasing trend. At the same time, China's manufacturing employment structure was becoming less and less specialised as GDP per capita was growing (Fig. 1, left 


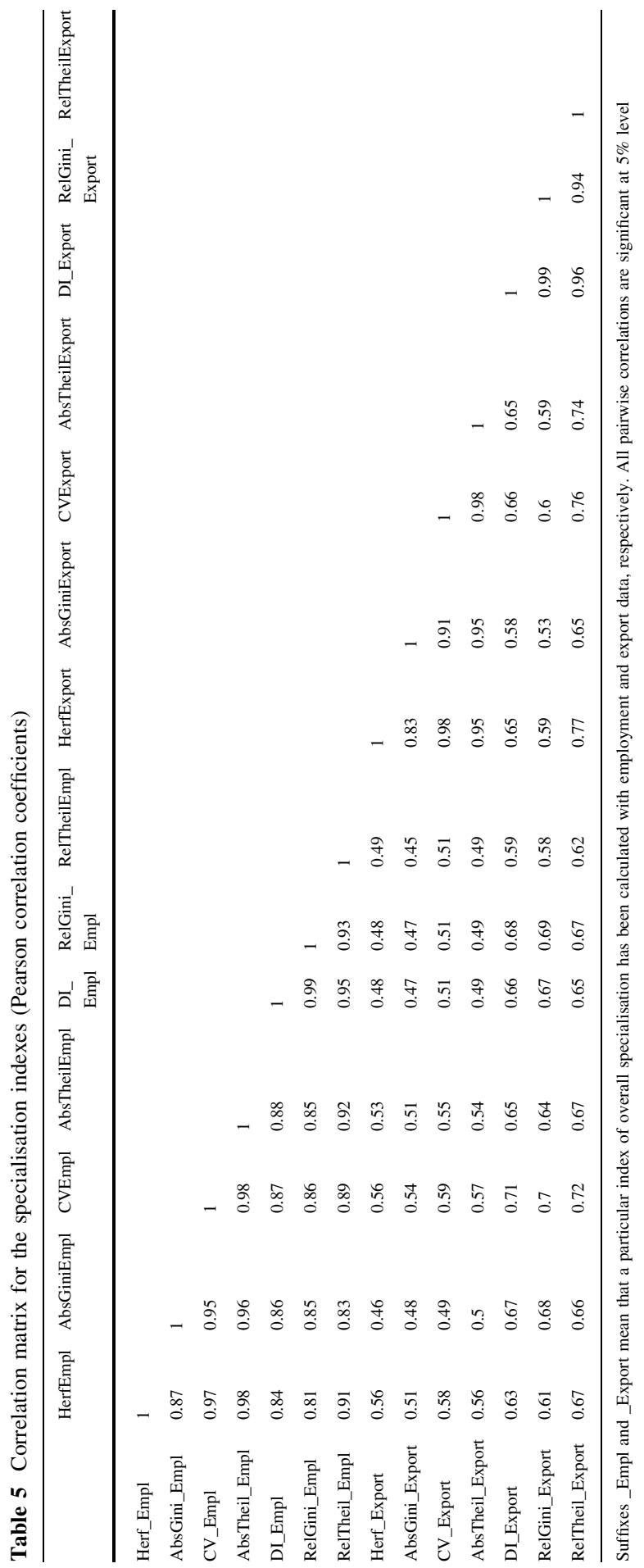



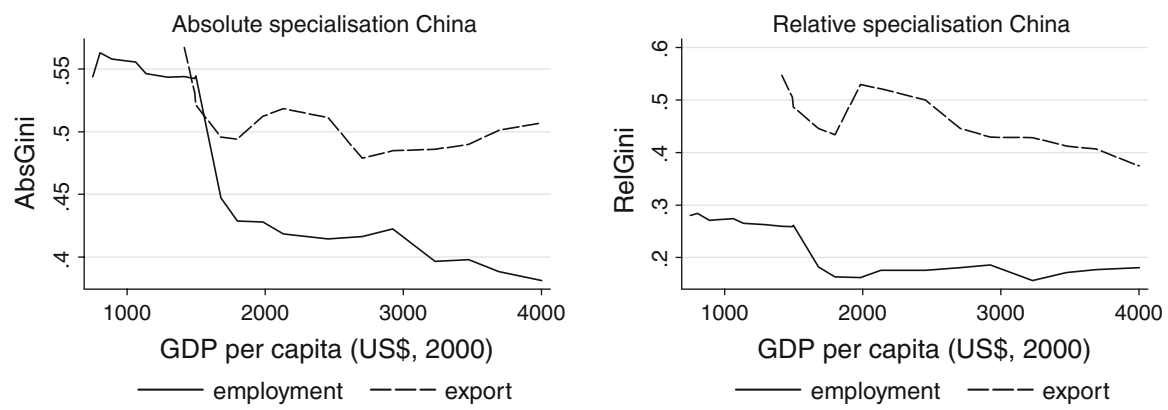

Fig. 1 Evolution of absolute and relative overall manufacturing specialisation along the development path-China (1986-2000). Specialisation measures (absolute and relative Gini index) calculated with employment and export data disaggregated into 17 manufacturing industries
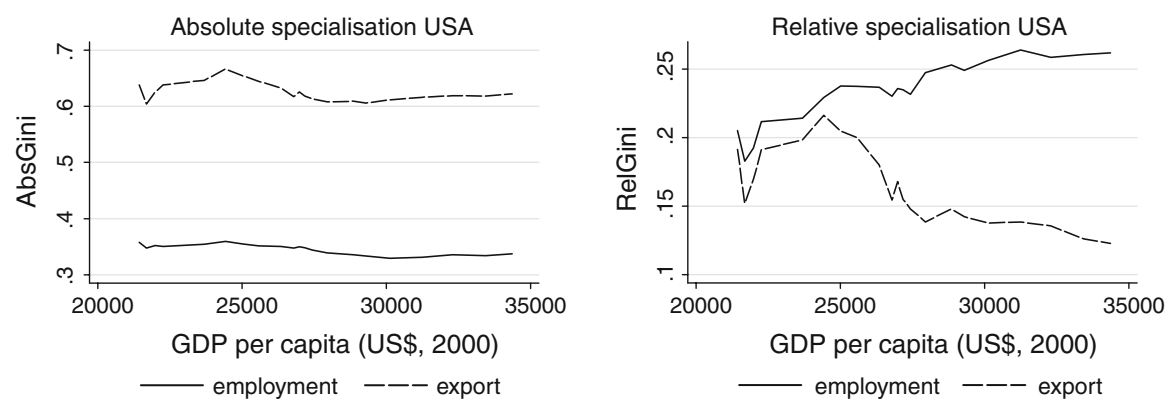

Fig. 2 Evolution of absolute and relative overall manufacturing specialisation along the development path-USA (1980-2000). Specialisation measures (absolute and relative Gini index) calculated with employment and export data disaggregated into 17 manufacturing industries

plot), but the analogical relative trend (Fig. 1, right plot, demonstrating Chinese specialisation in comparison with the typical structure in the 'world' benchmark) was much less pronounced. This is a clear sign that in addition to the fact that we should clearly distinguish between relative and absolute specialisation patterns, employment and export specialisation are not necessarily two sides of the same coin.

Such an observation is confirmed by the evidence for a developed country, the USA (Fig. 2), where the degree of absolute diversification of manufacturing employment and export structures was practically constant along the development path (Fig. 2, left plot) but, at the same time, at high levels of GDP per capita employment and export relative specialisation patterns were evolving in opposite directions (the former was rising, and the later was declining at GDP per capita levels above 25,000 US\$: Fig. 2, right plot). In other words, while the degree of internal US economic structure diversification remained rather constant, US export composition was converging towards the 'typical' international level of specialisation but employment structure in the USA was becoming more and more dissimilar from the rest of the world. 


\subsection{U-shaped relationship between specialisation and GDP per capita?} A critical evaluation

The two meaningful examples from the previous section prove that there is great variability in specialisation patterns along the paths of growth of single countries. Even though we argue that country-specific effects should be taken into account in the proper estimation of the overall 'specialisation curves,' we start with unconditional nonparametric evidence in order to confront our results with those already existing in the literature (Imbs and Wacziarg 2003; Koren and Tenreyro 2007; Cadot et al. 2007) and supporting U-shaped specialisation dynamics.

In the following figures we plot the whole range of nonparametric lowess curves approximating the evolution of employment and export overall specialisation along the GDP per capita development path. Instead of an arbitrary choice of the smoothing parameter, the degree of nonparametric span is defined by cross validation. $^{22}$ What emerges is that unconditional nonparametric evidence (based on pooled data, thus not allowing for the inclusion of country-fixed effects) indeed cannot be conclusive and is strongly dependant on the underlying method of overall specialisation measurement. This is probably the source of contrasting results presented in existing literature on overall specialisation dynamics. Employment and export lowess curves calculated with various specialisation indexes do not determine unambiguously the shape of the relationship between the degree of overall specialisation and GDP per capita levels. Some kind of unconditional U-shaped pattern is visible only in case of employment structures (which is in line with what Imbs and Wacziarg (2003) found), independently of the method of specialisation measurement: absolute (Fig. 3) or relative (Fig. 4).

However, export structures do not follow the same pattern, and we also reveal differences in absolute and relative export specialisation: the former remains rather constant (Fig. 5), while the latter decreases as countries move towards higher stages of development (Fig. 6).

The hypothesis of a U-shaped pattern of specialisation evolution along the development path can also be checked parametrically by estimating the following quadratic formulation:

$$
S P E C_{i t}=\beta_{0}+\beta_{1}\left(G D P p c_{i t}\right)+\beta_{2}\left(G D P p c_{i t}\right)^{2}+u_{i t}
$$

where $S P E C$ is one of the measures of overall specialisation, GDPpc is the level of GDP per capita, $i$ refers to countries, and $t$ refers to time. The estimation results (along with calculated turning points associated with the minimum level of overall specialisation along the curve) are presented in Table 6.

\footnotetext{
22 Following Bowman and Azzalini (1997), cross validation (CV) procedure defines a suitable level of smoothing by finding the compromise between bias and variance (the former increases, while the latter decreases as span grows) through the minimisation of mean integrated square error. For details see Hastie and Tibshirani (1990: 42-43). We have also tried to plot lowess specialisation curves for various arbitrarily chosen span levels $(0.3,0.5$ and 0.8$)$, and indeed their shapes are very sensitive to the choice of a span (available on request).
} 

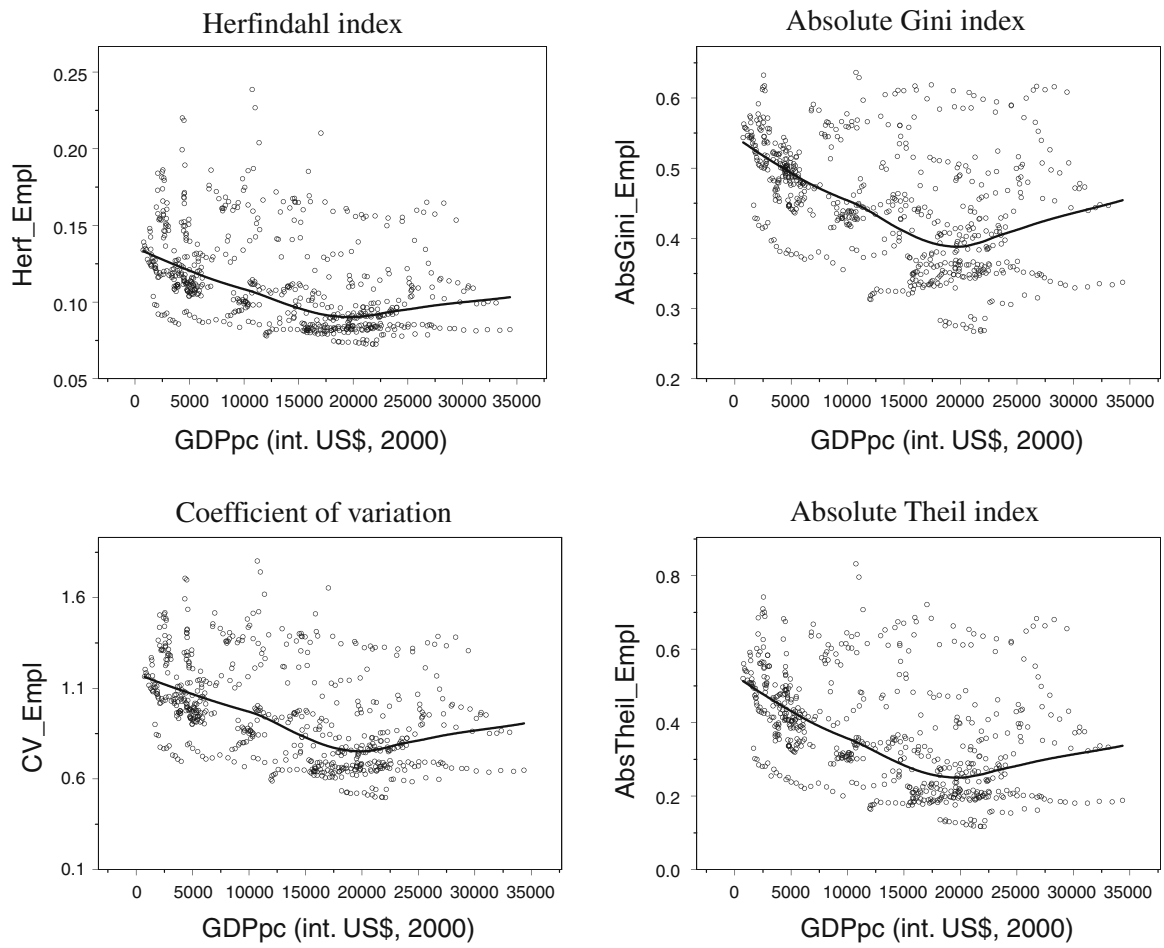

Fig. 3 Absolute employment specialisation along the development path (pooled lowess). Nonparametric span defined by cross validation. Measures of overall specialisation calculated with employment data, 17 manufacturing sectors, 32 countries, 1980-2000, 672 observations

Again, some kind of U-shaped pattern could be confirmed only in case of employment structures evolution with medium turning point occurring rather late. Note, however, that its estimated value is very sensitive to the measure of specialisation used and in case of employment patterns ranges between 12,500 and above 32,000 int. US\$, 2000. There is no robust evidence for a U-shaped export specialisation curve.

\section{Manufacturing despecialisation in the initial phase of economic development}

\subsection{Semiparametric estimation of the specialisation curve}

The following semiparametric plots of partial residuals permit us to reveal flexibly the nature of the relationship between specialisation measures and the level of GDP per capita after having controlled for country-specific characteristics. We now obtain a very clear result that holds for all types of specialisation and for all measures: compared to lowess estimation, the inclusion of FE reduces considerably the dispersion of points around the estimated general specialisation curves and the 

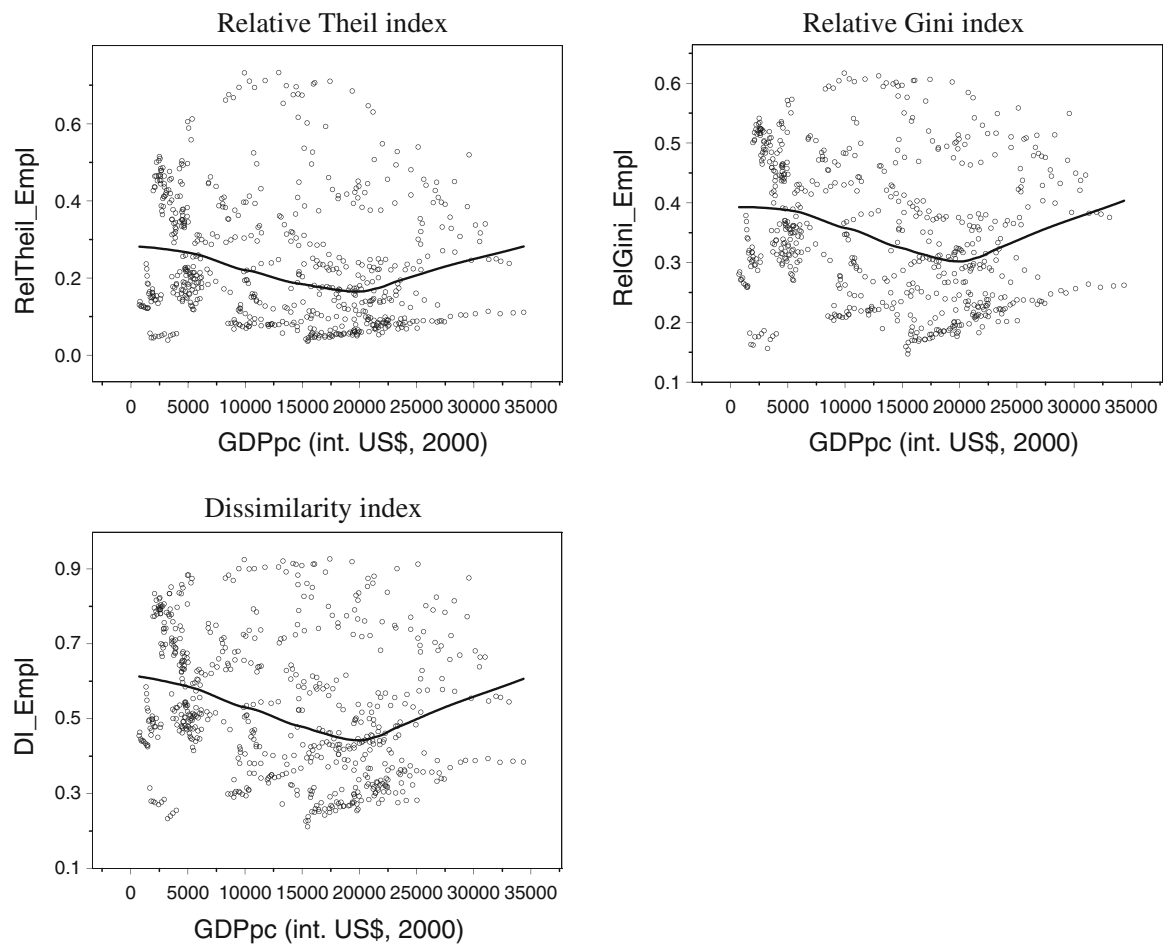

Fig. 4 Relative employment specialisation along the development path (pooled lowess). Nonparametric span defined by cross validation. Measures of overall specialisation calculated with employment data, 17 manufacturing sectors, 32 countries, 1980-2000, 672 observations

evolution of specialisation at the initial phase of growth is common to all specifications. It means that cross-country heterogeneity is an important factor whose omission may have led to contrasting results obtained within frameworks without FE.

In Fig. 7 we plot GAM employment absolute specialisation curves, and Fig. 8 presents relative curves obtained with employment data. Figures 9 and 10 present analogical export specialisation curves. Separate plots correspond to single GAM estimations as in (10) performed for both export and employment specialisation measured in absolute and relative terms. ${ }^{23}$

The initial phase of economic development is characterised by increasing diversification, up to the level of around 10,000 int. US\$ (2000) we can observe the tendency of decreasing manufacturing specialisation. This result holds for various specialisation measures (absolute and relative) and two types of basic data (employment and export statistics). The initial tendency is robust; only absolute export specialisation shows a very weak tendency towards a slightly increasing

\footnotetext{
${ }^{23}$ Note that in case of semiparametric methods the choice of the value of span is less immediate and cannot be determined on the base of cross validation criteria as in case of lowess method. We apply 0.5 span and then, in the robustness checks section, confront the results with those obtained with other span values.
} 

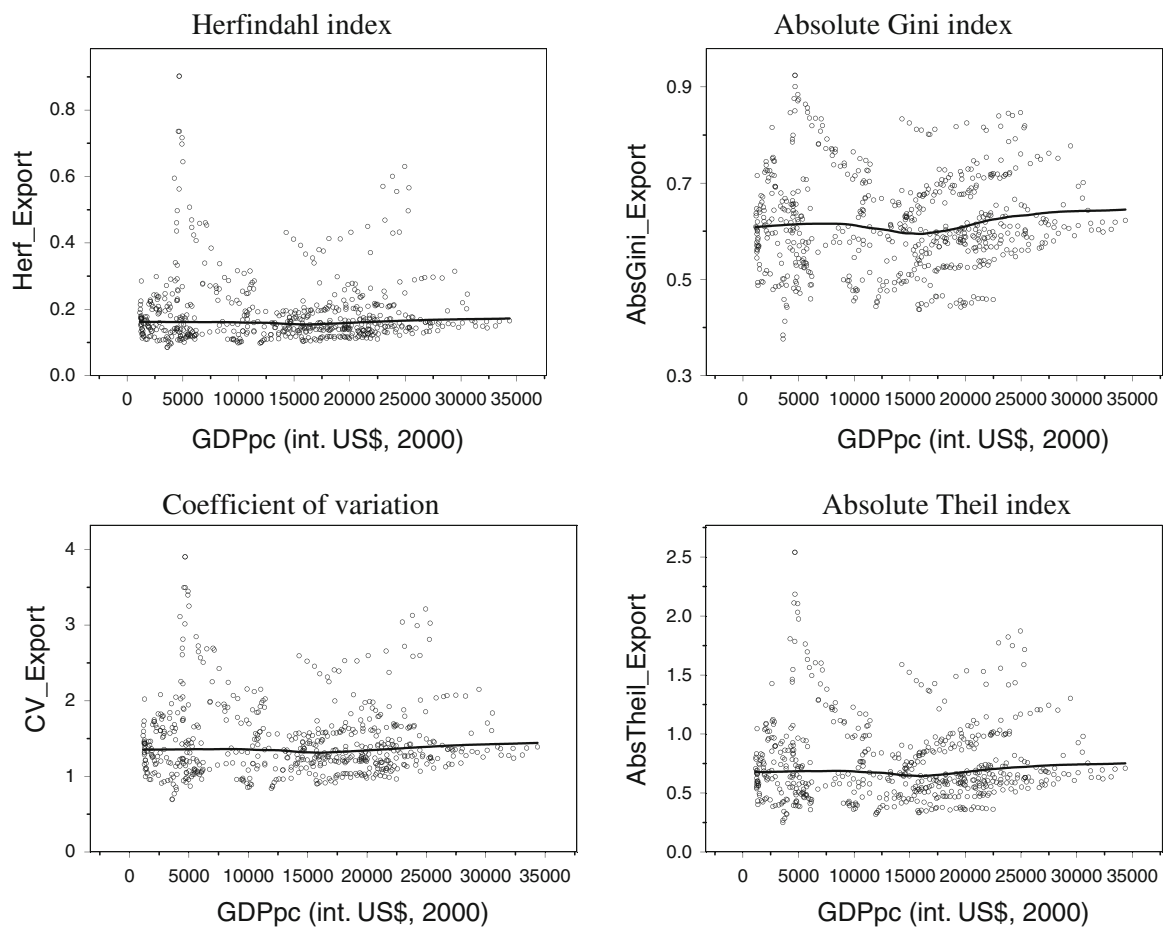

Fig. 5 Absolute export specialisation along the development path (pooled lowess). Nonparametric span defined by cross validation. Measures of overall specialisation calculated with export data, 17 manufacturing sectors, 32 countries, 1980-2000, 606 observations

trend at the higher levels of development (which confirms the importance of distinguishing between absolute and relative patterns of diversification and is in line with the previous findings). In Table 7 we present the statistical significance of the nonparametric component, and the general result is robust: the nonparametric component (development level) is significant in determining the nonlinear evolution of overall specialisation along the path of growth.

Note that our comparative exercise allows us to confront all the findings presented so far in the literature that appear to be contrasting with each other due to differences in the way of specialisation measurement. To summarize, if we take into account cross-country heterogeneity (and especially if we confront country-specific patterns with the overall trend through the application of relative indexes) both employment and export relative specialisation appear to decrease in the initial phase of economic development (Figs. 8, 10). The nations initially tend to have rather poorly diversified manufacturing structures with respect to the overall benchmark trend (which can be dangerous from the point of view of major risk associated with such a situation), but in the course of growth this tendency weakens and diversification opportunities appear. In other words, as GDP per capita grows, the degree of overall specialisation in a 'typical' country with respect to the rest of the 'world' tends to decrease along the development path. 

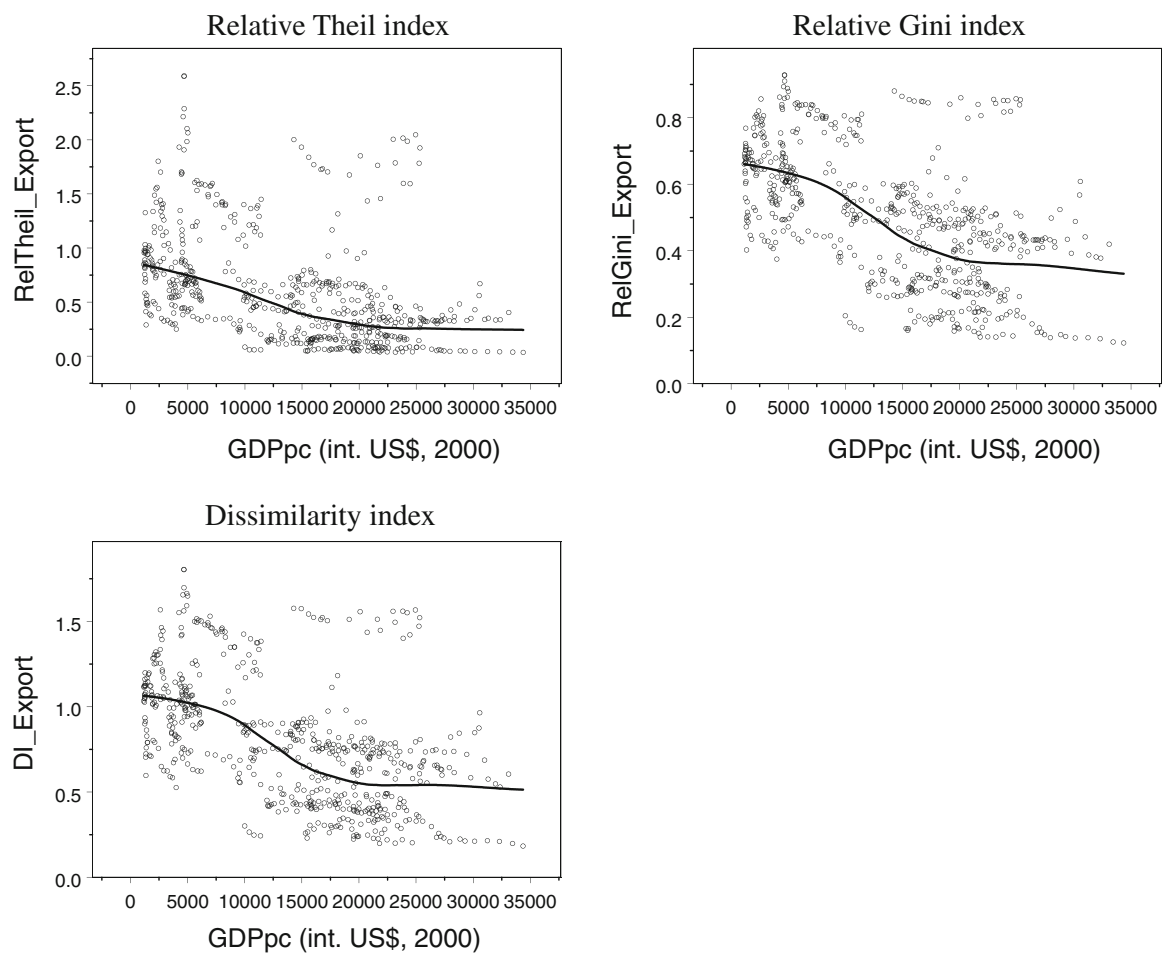

Fig. 6 Relative export specialisation along the development path (pooled lowess). Nonparametric span defined by cross validation. Measures of overall specialisation calculated with export data, 17 manufacturing sectors, 32 countries, 1980-2000, 606 observations

\subsection{Robustness checks ${ }^{24}$}

First of all, we have controlled the robustness of our result for changes in the disaggregation scheme within the same panel of countries. Maintaining a constant set of sectors for every country through time (but variable across countries), we have computed all four previously used absolute specialisation measures with sectoral employment and export statistics coming from the same sources as before (UNIDO and UN COMTRADE). ${ }^{25}$ The results do not change; GAM estimations with country-fixed effects again prove that countries diversify along the development path.

Next, we applied an alternative relative measure of overall specialisation: the median of the Balassa index (BImed), as suggested by de Benedictis and Tamberi (2004), which, contrary to the measures we have used, is negatively related to the degree of overall specialisation. BImed calculated with both employment and export

\footnotetext{
24 All of the results referring to this section are available on request.

25 Note that in this case it is not possible to calculate relative specialisation measures, which require maintaining a constant set of sectors across countries and through time.
} 


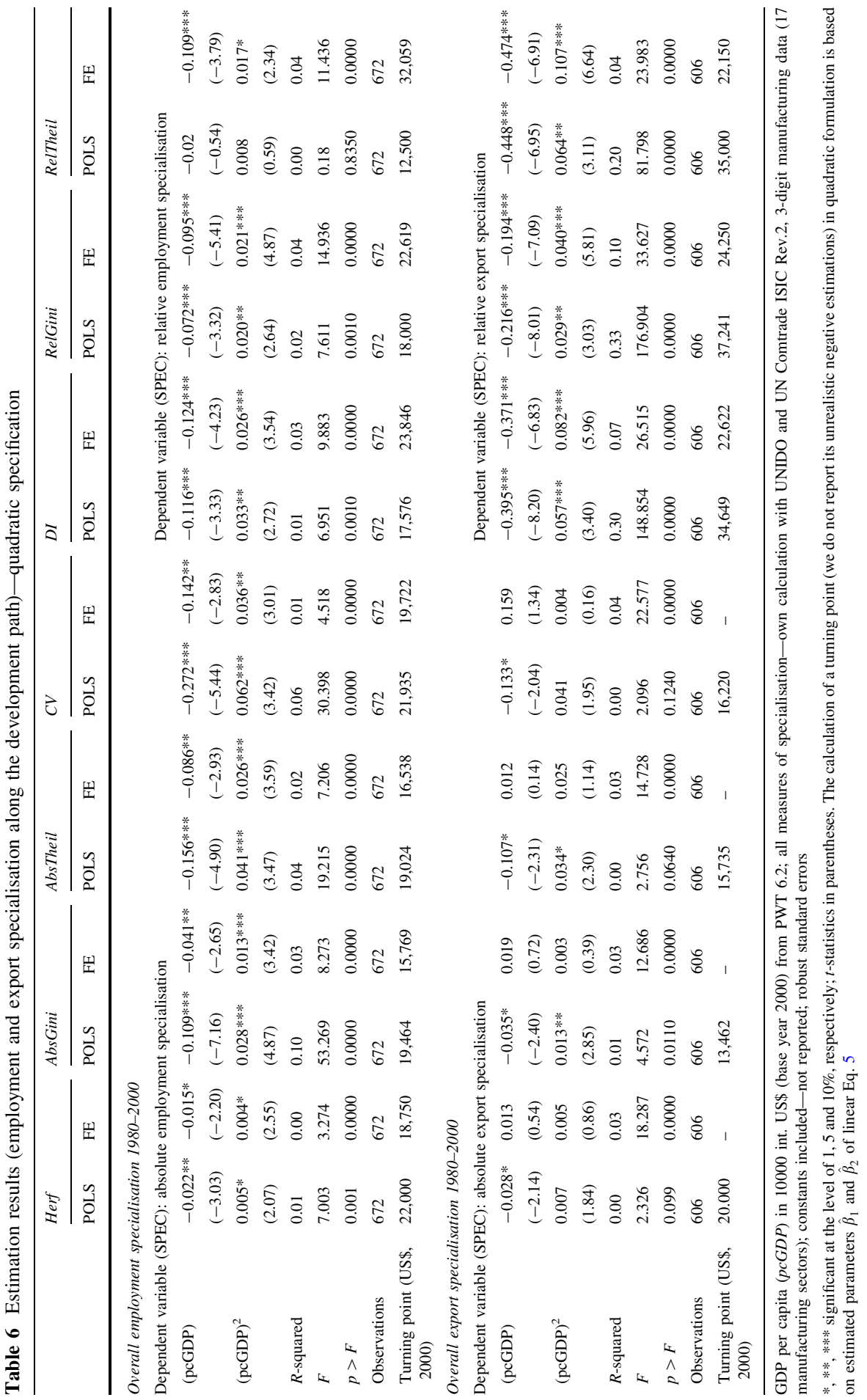



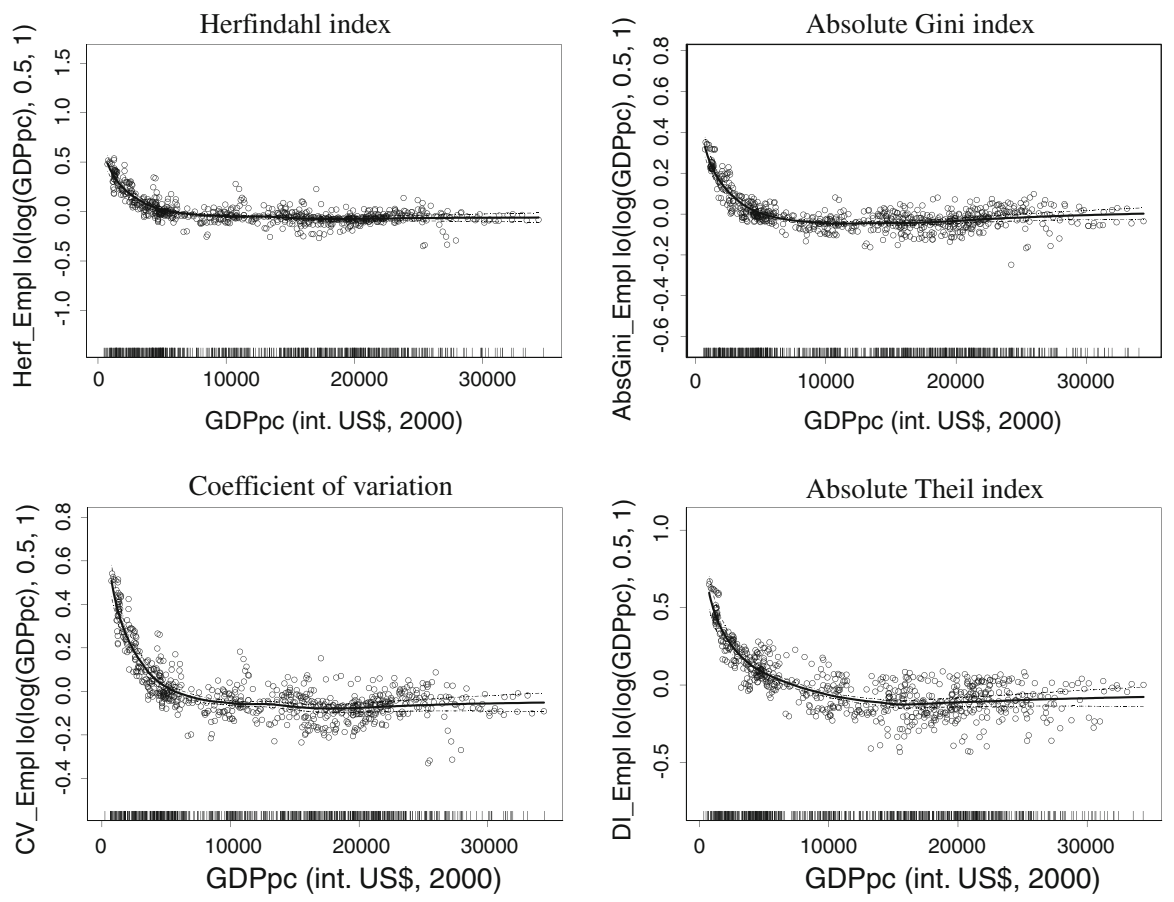

Fig. 7 Semiparametric absolute employment specialisation curves (GAM with country FE). Separate plots refer to semiparametric GAM estimations of the relationship between overall absolute employment specialisation (vertical axis) and the development level (horizontal axis). Nonparametric span $=0.5$. Overall absolute specialisation measures calculated with employment data, 17 manufacturing sectors, 1980-2000, 32 countries

statistics tends to grow along the initial phase of the GDP per capita expansion path, which is a sign of increasing diversification.

We have also controlled for changes in the value of nonparametric span (denoting the degree of smoothing) applied in baseline GAM estimations of specialisation curves. Different values of span (0.3, 0.5 and 0.8$)$ do not influence the shape of the decreasing relationship between overall specialisation and GDP per capita levels when country-fixed effects are accounted for.

Next, we applied a standard fixed-effect model linking specialisation with GDP per capita levels. The coefficients associated with the development level are negative and in most cases highly significant. However, standard plots of partial residuals, albeit having the shapes similar to those obtained through GAM procedure, reveal nonlinearity in the data and call for applying flexible methods of estimation.

Finally, we controlled whether the result holds in case of a bigger set of countries and a stronger disaggregation. We calculated the degree of overall specialisation in 60 countries (1985-2004) with export statistics coming, as before, from the UN COMTRADE database but disaggregated into 149 manufacturing product groups classified according to SITC Rev.2, 3-digit scheme and, as before, into 28 ISIC 

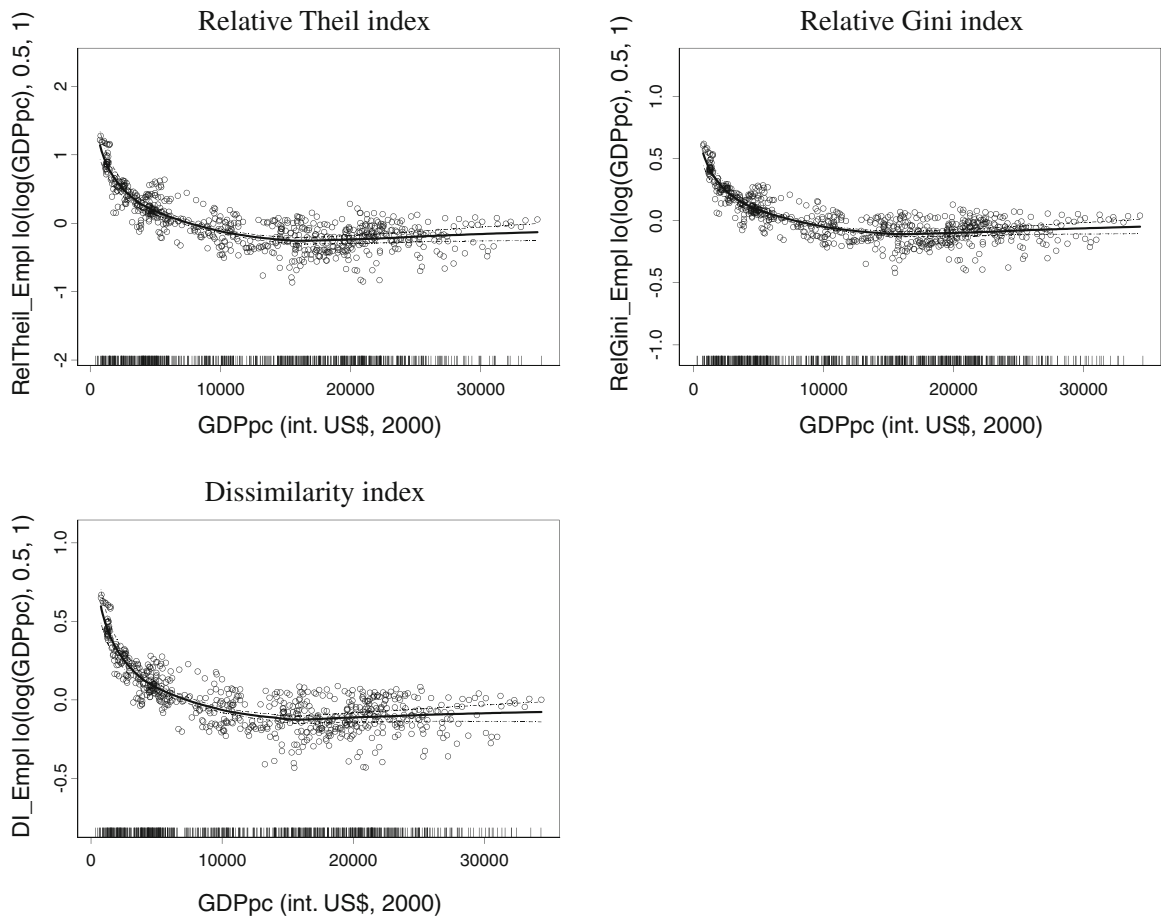

Fig. 8 Semiparametric relative employment specialisation curves (GAM with country FE). Separate plots refer to semiparametric GAM estimations of the relationship between overall relative employment specialisation (vertical axis) and the development level (horizontal axis). Nonparametric span $=0.5$. Overall relative specialisation measures calculated with employment data, 17 manufacturing sectors, 1980-2000, 32 countries

Rev.2, 3-digit sectors. Semiparametric specialisation curves (with fixed effects) obtained with Theil index (in absolute and relative versions) are very similar to those already described and confirm the tendency towards despecialisation at the beginning of the development process.

\section{Concluding remarks}

The aim of this study was to contribute to the literature on the specialisation-GDP per capita nexus by adopting a unifying approach for the study of overall specialisation dynamics in an international context. Given the contradictions appearing in the existing empirical evidence on the evolution of industrial and trade specialisation along the development process, we contribute by providing analogous frameworks for the study of these two dimensions of economic diversification. The results referring to employment and export specialisation are directly comparable thanks to the thorough reorganisation of the original data sets, the maintenance of the same set of countries and time span, as well as the application of a unique disaggregation scheme (ISIC Rev.2, 3-digit). In addition, we have adopted a wide 

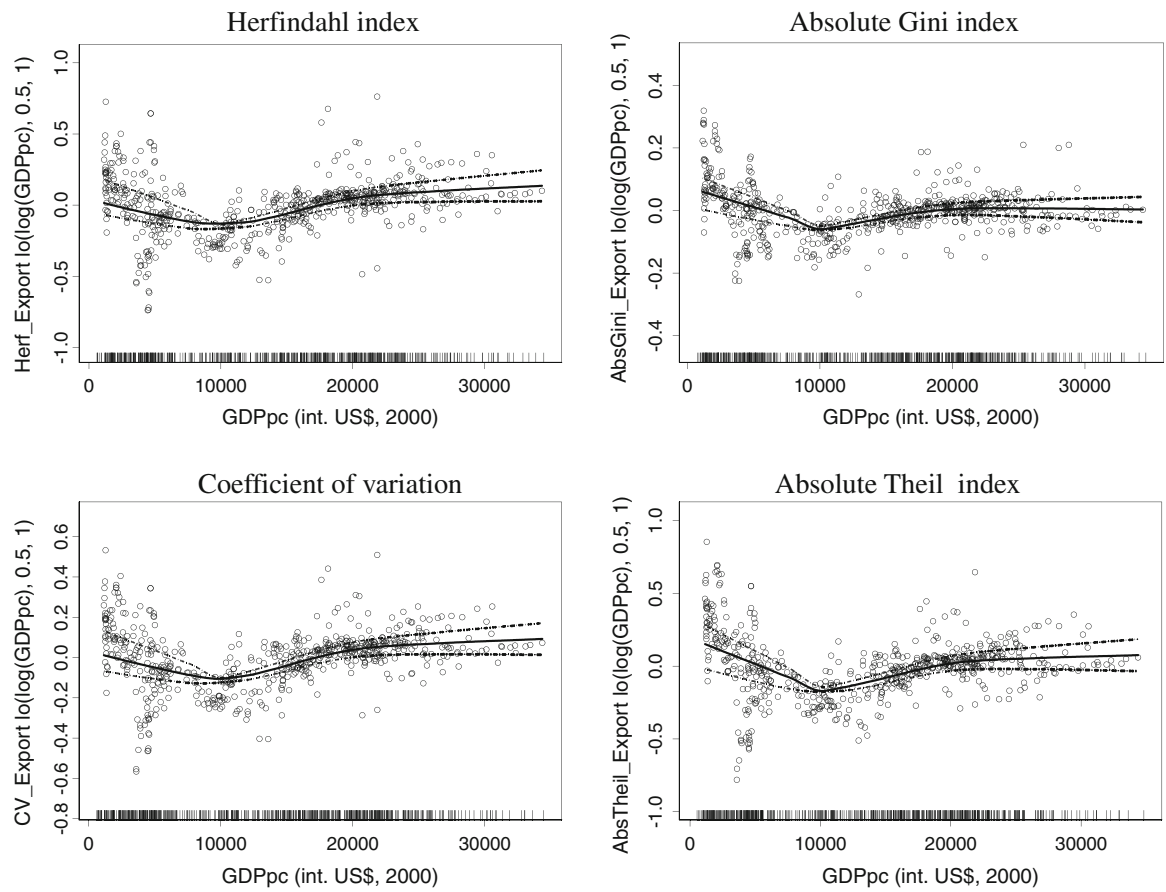

Fig. 9 Semiparametric absolute export specialisation curves (GAM with country FE). Separate plots refer to semiparametric GAM estimations of the relationship between overall absolute export specialisation (vertical axis) and the development level (horizontal axis). Nonparametric span $=0.5$. Overall absolute specialisation measures calculated with export data, 17 manufacturing sectors, 19802000, 32 countries

range of specialisation measures that allowed us to trace the differences between relative and absolute specialisation patterns-something that is lacking in the existing literature.

We have been particularly interested in estimating the so-called 'specialisation curve' describing the evolution of sectoral division of economic activity along the development path of GDP per capita. In order to avoid imposing the nature of a relationship between the two variables of interest, we have chosen to give preference to nonparametric and semiparametric estimation techniques. Given that the evolution of overall specialisation along the development process described by lowess curves is sensitive to the type of the data and does not take into account inbuilt cross-country heterogeneity, we have argued to use semiparametric GAM estimations with country-fixed effects. We have demonstrated that unconditional measurement of manufacturing specialisation is in general sensitive to the methodological setting applied. However, after taking into account country-specific heterogeneity, we find the general tendency of decreasing specialisation at the beginning of the development process. The tendency towards diversification is visible both in employment and export patterns and is particularly evident if we consider single countries in a setting allowing for the detection of relative trends of 

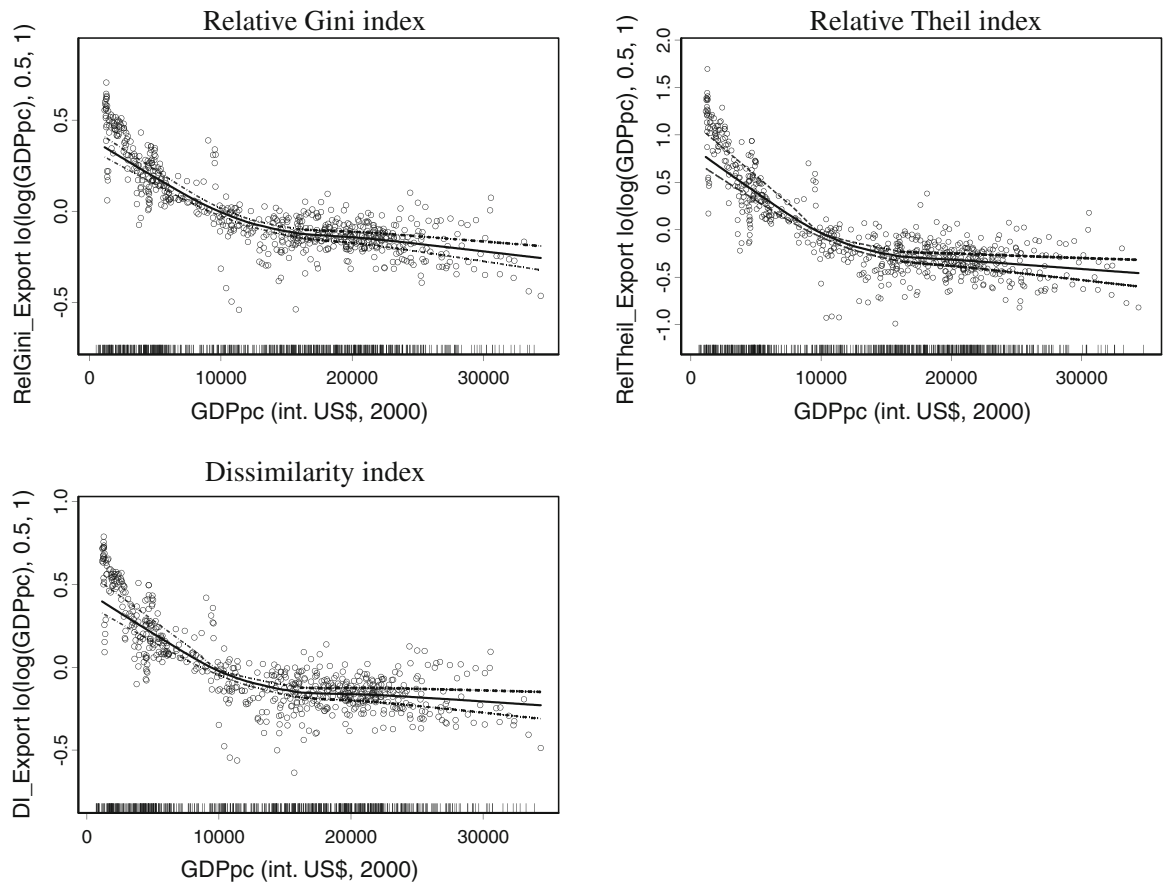

Fig. 10 Semiparametric relative export specialisation curves (GAM with country FE). Separate plots refer to semiparametric GAM estimations of the relationship between overall relative export specialisation (vertical axis) and the development level (horizontal axis). Non-parametric span $=0.5$. Overall relative specialisation measures calculated with export data, 17 manufacturing sectors, 19802000, 32 countries

Table 7 Significance of nonparametric component in GAM estimations with FE-overall specialisation versus GDP per capita (1980-2000)

\begin{tabular}{llllllll}
\hline Specialisation measure & Herf & CV & AbsGini & AbsTheil & RelGini & RelTheil & DI \\
\hline $\begin{array}{l}\text { Employment specialisation } \\
\text { NparF }\end{array}$ & 41.18 & 54.11 & 75.49 & 72.68 & 24.14 & 35.84 & 24.70 \\
$\begin{array}{l}p(F) \\
\text { Observations }\end{array}$ & $(0.0000)$ & $(0.0000)$ & $(0.0000)$ & $(0.0000)$ & $(0.0000)$ & $(0.0000)$ & $(0.0000)$ \\
Export specialisation & 672 & 672 & 672 & 672 & 672 & 672 & 672 \\
NparF & & & & & & & \\
p F $)$ & 26.46 & 30.84 & 27.53 & 33.02 & 7.56 & 9.42 & 9.99 \\
Observations & $(0.0000)$ & $(0.0000)$ & $(0.0000)$ & $(0.0000)$ & $(0.0000)$ & $(0.0000)$ & $(0.0000)$ \\
\hline
\end{tabular}

GAM estimations refer to a model with a specialisation measure as the dependent variable, GDP per capita as nonparametric component and country dummies as linear components; nonparametric $\operatorname{span}=0.5$

specialisation. In the initial phase of growth, countries tend to diversify their employment and export structures. The result holds for various measures of specialisation, estimation techniques, and levels of sectoral disaggregation. 
Acknowledgments The author would like to thank Massimo Tamberi for his help, as well as the participants of ETSG (Athens, 2007) and ECINEQ (Berlin, 2007) conferences for valuable comments and suggestions on an earlier version of the paper. All the remaining errors are of the author's responsibility.

\section{References}

Acemoglu, D., \& Zilibotti, F. (1997). Was Prometheus unbound by chance? Risk, diversification and growth. Journal of Political Economy, 105(4), 709-751.

Aiginger, K., Boheim, M., Gugler, K., Pffafermayr, M., \& Wolfmayr-Schnitzer, Y. (1999). The competitiveness of European industry. Brussels: Working Document of the Services of the European Commission.

Aiginger, K., \& Davies, S. W. (2004). Industrial specialisation and geographic concentration: Two sides of the same coin? Not for the European Union. Journal of Applied Economics, 7(2), 231-248.

Amiti, M. (1999). Specialisation patterns in Europe. Weltwirtschaftliches Archiv/Review of World Economics, 135(4), 573-593.

Bowman, A. W., \& Azzalini, A. (1997). Applied smoothing techniques for data analysis. Oxford: Clarendon Press.

Brülhart, M. (1998). Trading places: Industrial specialisation in the European Union. Journal of Common Market Studies, 36(3), 319-346.

Brülhart, M. (2001). Evolving geographical concentration of European manufacturing industries. Weltwirtschaftlliches Archiv/Review of World Economics, 137(2), 215-243.

Cadot, O., Carrère, C., \& Strauss-Kahn, V. (2007). Export diversification: What's behind the hump? (CEPR discussion paper 6590). Centre for Economic Policy Research, London.

Cleveland, W. (1979). Robust locally weighted regression and smoothing scaterplots. Journal of the American Statistic Association, 74(368), 829-836.

Cowell, F. (1995). Measuring inequality. London: Prentice Hall/Harvester Wheatsheaf.

de Benedictis, L., Gallegati, M., \& Tamberi, M. (2009). Overall trade specialisation and economic development: Countries diversity. Review of World Economics/Weltwirtschaftliches Archiv, 145(1), 37-56.

de Benedictis, L., \& Tamberi, M. (2004). Overall specialisation empirics: Techniques and applications. Open Economies Review, 15(4), 323-346.

Friedman, J. H., \& Stuetzle, W. (1981). Projection pursuit regression. Journal of the American Statistical Association, 76, 817-823.

Grossman, G., \& Helpman, E. (1991). Innovation and growth in the global economy. Cambridge, MA: MIT Press.

Hastie, T. J., \& Tibshirani, R. J. (1987). Generalized additive models. Some applications. Journal of American Statistical Association, 82(397), 371-386.

Hastie, T. J., \& Tibshirani, R. J. (1990). Generalized additive models. London: Chapman and Hall.

Hausmann, R., Hwang, J., \& Rodrik, D. (2007). What you export matters. Journal of Economic Growth, 12(1), 1-25.

Heston, A., Summers, R., Aten, B. (September 2006). Penn World Table version 6.2. Pennsylvania: Centre for International Comparisons of Production, Income and Prices, University of Pennsylvania.

Iapadre, L. (2001). Measuring international specialisation. International Advances in Economic Research, 7(2), 173-183.

Imbs, J., \& Wacziarg, R. (2003). Stages of diversification. American Economic Review, 93(1), 63-86.

Kalemli-Ozcan, S., Sørensen, B. E., \& Yosha, O. (2003). Risk sharing and industrial specialisation: Regional and international evidence. American Economic Review, 93(3), 903-918.

Koren, M., \& Tenreyro, S. (2007). Volatility and development. Quarterly Journal of Economics, 122(1), 243-287.

Krugman, P. (1991). Geography and trade. Cambridge, MA: MIT Press.

Laursen, K. (2000). Do export and technological specialisation coevolve in terms of convergence or divergence? Evidence from 19 OECD countries, 1971-1991. Journal of Evolutionary Economics, 10(4), 415-436.

Midelfart-Knarvik, K. H., Overman, H. G., Redding, S. J., \& Venables, A. J. (2000). The location of European industry. (Directorate General for Economic and Financial Affairs Economic Paper 142). Brussels: European Commission. 
Pagan, A., \& Ullah, A. (1999). Nonparametric econometrics. Cambridge: Cambridge University Press.

Plümper, T., \& Graff, M. (2001). Export and economic growth. Review of International Political Economy, 8(4), 661-688.

Schimek, M. (2000). Smoothing and regression. Approaches, computation and application. New York: Wiley.

Schimek, M., \& Turlach, B. (2000). Additive and generalized additive models. In M. Schimek (Ed.), Smoothing and regression. Approaches, computation and application (pp. 277-327). New York: Wiley.

Wood, S. N. (2006). Generalised additive models. An introduction with R. London: Chapman and Hall.

Wörz, J. (2005). Dynamics of trade specialisation in developed and less developed countries. Emerging Markets Finance and Trade, 41(3), 92-110.

United Nations Industrial Development Organization (UNIDO). (2006). Industrial statistics database 2006. Manchester: ESDS International, University of Manchester.

United Nations Statistical Division (UNSD). (2007). Commodity trade database (COMTRADE), available through World Bank's world integrated trade solution (WITS). http://www.wits. worldbank.org. 